\title{
Entrepreneurship, Innovation and Aviation
}

$\mathrm{T}$ he edition number 2, volume 7, of Aviation in Focus brings two interesting articles about different aspects of management in Aeronautical Sciences. The first article - Analysis of Ticket Price in the Airline Industry from the Perspective of Operating Costs, Supply and Demandpresents the correlation between different factors that may influence Air Ticket Price. The second article - A Competitividade como Fator Negativo na Aviação Brasileira - reviews the current regulation of the Brazilian Aeronautical sector, discussing it in relation to the competition between Brazilian air companies.

If we take a broader look at these two articles, we can observe the influence that management, entrepreneurship and innovation has on them both. The discussion regarding ticket price and competitiveness is a clear management issue but is also related to innovation, since innovative activity may improve the competitive advantage of companies, while the entrepreneurial activity of new air companies may influence the relationship between supply and demand in a specific sector. In this sense, both entrepreneurship and innovation are the main themes of this editorial.

Looking back at the beginning of the 20th century, the main Brazilian entrepreneur in the aviation sector was Santos Dumont. This great aviation pioneer was honoured during the opening ceremony of the 2016 Summer Olympic Games held in Rio de Janeiro, and his inventions, the 14-bis and Demoiselle, were among the first airplanes registered worldwide. Santos Dumont was an entrepreneur and innovator, developing a new technology that was later explored by different companies, also being one of the main technologies used in WWI. During the testing of his airplanes, Santos Dumont recognised the need to develop side technologies to assist him while flying, also making him an innovator outside the aeronautical industry.

Brazilian commercial aviation has many examples of pioneering entrepreneurial endeavour, such as Condor and VARIG. Condor was a subsidiary of the German Company Lufthansa and started its activities on a Rio de Janeiro-Florianopolis flight in 1927. Later in the same year, the first Brazilian air company was founded, VARIG, becoming one of the main companies in Latin America. More recently, in 2000, another important business case was established in Brazil, with the founding of GOL, the first Brazilian low-cost airline company.

In line with the entrepreneurial spirit of the Aeronautical and Aerospace industry, the Microgravity Centre - an aerospace research centre established at PUCRS - has launched

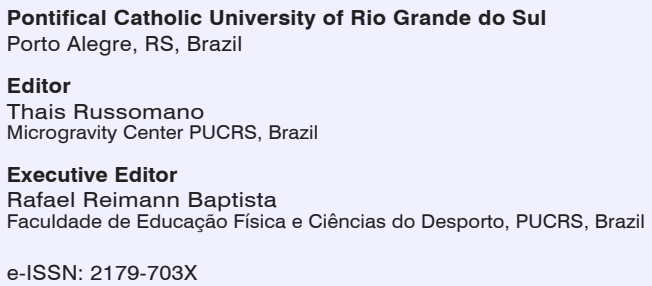

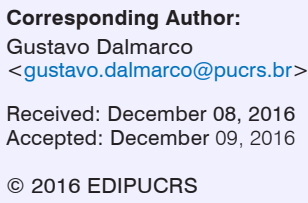

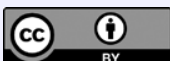

This work is licensed under a

Creative Commons-Attribution 4.0 International. http://creativecommons.org/licenses/by/4.0/ 
the MicroG Entrepreneur, a project that aims to stimulate entrepreneurial activities among students and researchers. The MicroG Entrepreneur was recently responsible for organizing the Act in Space event, a competition aimed at stimulating entrepreneurs to develop new products or services through an innovative business model (similar to a hackathon). On this occasion, the competition was based on the use of space technologies for non-space applications. The event happened in May of 2016 and the two winning groups are receiving entrepreneurial orientation to improve their business plans in order to apply for a business incubator. The MicroG Entrepreneur is also presently working on a training program for pilots and athletes, using equipment developed for research activities in Aerospace Physiology.

Motivated by the entrepreneurial possibilities of the aviation sector, the MicroG Entrepreneur aims to become a bridge between the academic world and the market, promoting the development of a new generation of $21^{\text {st }}$ century Santos Dumonts and Varigs from the school of aeronautical sciences of PUCRS.

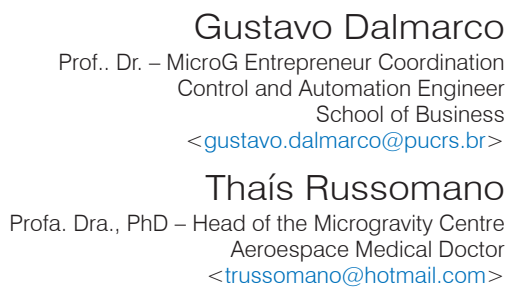

